Acta Crystallographica Section B

Structural

Science

ISSN 0108-7681

\section{J. M. Montejo-Bernardo, S. García-Granda* and A. Fernández-González}

Departamento de Química Física y Analítica, Facultad de Química, Universidad de Oviedo, E-33006 Asturias, Spain

Correspondence e-mail: sgg@uniovi.es
(C) 2010 International Union of Crystallography Printed in Singapore - all rights reserved

\title{
Structures of relevant ammonium salts in fertilizers
}

The crystal structures of two double salts of ammonium nitrate (AN) and ammonium sulfate (AS) are reported. The double salts $2 \mathrm{NH}_{4} \mathrm{NO}_{3} \cdot\left(\mathrm{NH}_{4}\right)_{2} \mathrm{SO}_{4} \quad(2 \mathrm{AN} \cdot \mathrm{AS})$ and $3 \mathrm{NH}_{4} \mathrm{NO}_{3} \cdot-$ $\left(\mathrm{NH}_{4}\right)_{2} \mathrm{SO}_{4}(3 \mathrm{AN} \cdot \mathrm{AS})$ show a very similar crystal structure packing with alternating layers of anions and cations. The solid-state ionic distribution is controlled by an extensive hydrogen-bonding network with ammonium groups as the donors and $\mathrm{O}$ atoms acting as the acceptors. Crystallographic studies were conducted at both room temperature (293 K) and $100 \mathrm{~K}$. Increasing the temperature involves shortening the $\boldsymbol{b}$ axis in the case of the 3AN.AS salt. Quantification of fertilizer mixtures using the Rietveld method was also carried out by means of the structural models reported in this paper for both salts.

\section{Introduction}

Ammonium nitrate (AN) and ammonium sulfate (AS) have a widely reported ability to form double salts. In fact, the 2AN.AS (2.1) and 3AN.AS (3.1) salts have been known for a century (Schreinemakers \& Hoenen, 1909), although they still have to be fully characterized. X-ray powder diffraction (XPRD) profiles have been used to guess their cell parameters as well as the possible space group (Jänecke et al., 1927; Bokii \& Burovaya, 1937; Sokolov, 1938; Smith et al., 1962; Misovic \& Ramasechan, 1963) and these profiles are still used to identify both double salts (Srinivasa et al., 1964; Harrison \& Sturges, 1984). Although other double salts were proposed, AN.AS (Sokolov, 1938; Srinivasa et al., 1964), 3AN.2AS (Osaka \& Inouye, 1925) and 4AN.AS (Sokolov, 1938), thermodynamic studies have demonstrated that only $2 \mathrm{AN} \cdot \mathrm{AS}$ and $3 \mathrm{AN} \cdot \mathrm{AS}$ salts can arise from the combination of AN and AS (Clegg et al., 1998; Wexler \& Clegg, 2002; Amundson et al., 2006). Furthermore, thermodynamics shows that $3 \mathrm{AN} \cdot \mathrm{AS}$ is a metastable salt which gradually evolves into the stable salt 2AN.AS (Ling \& Chan, 2007). A monohydrate double salt, however, has been reported, although its structure remains unsolved (Ghosh et al., 1965).

Recently, 2AN.AS and 3AN.AS salts have been widely studied and characterized as particles in aerosols (Martin et al., 2003, 2004; Schlenker et al., 2004; Schlenker \& Martin, 2005; Ling \& Chan, 2007; Bothe \& Beyer, 2007). In addition, these two salts are also widely used in fertilizers. Ammonium sulfate nitrate (ASN) is one of the first synthetic fertilizers. It is a source of primary (nitrogen) and secondary (sulfate) nutrients and has been used for nearly the last hundred years. Historically, the term 'ammonium sulfate nitrate' has not referred to a specific chemical composition with fixed properties. Rather it has been used in the fertilizer lexicon to describe mixtures of $\mathrm{AN}$ and $\mathrm{AS}$ in different percentages
Received 9 February 2010

Accepted 26 April 2010

This paper is dedicated to the memory of Professor José Manuel Concellón and to the emeritus Professor Fermín Gómez-Beltrán 


\section{Table 1}

Experimental details.

Experiments were carried out with Mo $K \alpha$ radiation. $\mathrm{H}$ atoms were treated by a mixture of independent and constrained refinement.

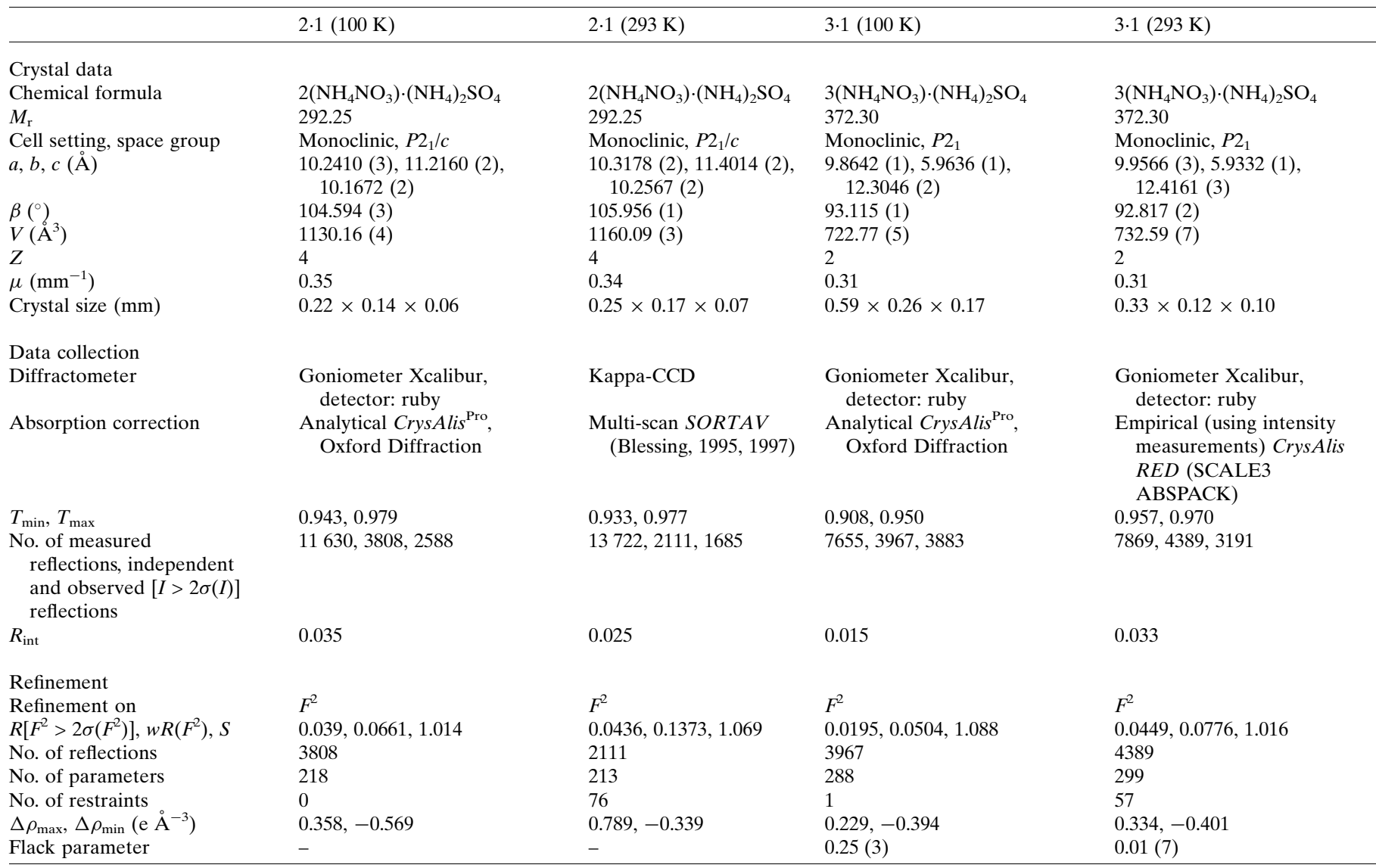

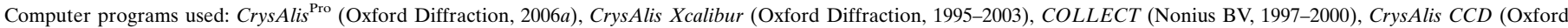

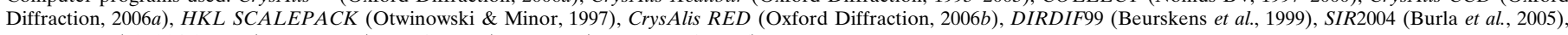
SHELXL97 (Sheldrick, 2008), ORTEP3 (Farrugia, 1997) Mercury (Macrae et al., 2006).

(Meline et al., 1968; Highsmith et al., 2002). The Association of American Plant Food Control Officials (AAPFCO, 2009) has defined ASN as a double salt of ammonium nitrate and ammonium sulfate with a minimum nitrogen content of $26 \%$. Therefore, salts $2 \cdot 1$ and $3 \cdot 1$ can be considered ASN, as their nitrogen content is 28.76 and $30.10 \%$, respectively. These double salts are more efficient in the nutrient delivery process than ammonium nitrate alone. Moreover, they enrich the soil with sulfur, which has been deficient in many soils in recent years. The 2AN.AS salt is the one most commonly used as the base material in fertilizers because of its lower nitrate percentage $(42.44 \%)$, the final ratio of both sulfate and nitrate nutrients being adjusted by adding inert substances, such as dolomite or anhydrous calcium sulfate among others, together with pure ammonium sulfate.

In this paper we present the crystal structures of the two known double salts at both room temperature and $100 \mathrm{~K}$ using single-crystal X-ray diffraction. Both structures exhibit a dense hydrogen-bond network, with a similar arrangement of cations and anions. The 3.1 salt behaves oddly in one of the cell axes on decreasing the temperature and shows a temperature-dependent disorder of one nitrate group. The structural determination of both salts allowed the accurate quantification of different real samples containing both pure double salts, free AS and other minor phases using XRPD (with a bidimensional detector) and a Rietveld fit of the experimental data. A major contribution of this study to the state-of-the-art lies in the possibility of quantification, as XRPD is employed nowadays in the fertilizer field only as a routine tool for identification (Coates \& Woodard, 1963; Malquori \& Cecconi, 1964; Lehr et al., 1967; Highsmith et al., 2002; Jassal \& Kumar, 2004).

\section{Experimental}

\subsection{Samples}

A suitable single crystal of the $3 \mathrm{AN}$.AS salt was selected from a solid (sample S3) obtained through Smith et al.'s (1962) method. An appropriate single crystal of the 2AN.AS salt was chosen from an industrial sample (sample S2) provided by the company Fertiberia, as was the nitrosulfate fertilizer sample (sample S1). 


\subsection{Experimental data}

Room-temperature data collection for the $2 \cdot 1$ salt was performed on a Nonius Kappa CCD single-crystal diffractometer using Mo $K \alpha$ radiation $(\lambda=0.71073 \AA)$. For the $3 \cdot 1$ salt, data collection was performed on an Oxford Diffraction Gemini S single-crystal diffractometer using Mo $K \alpha$ radiation $(\lambda=0.71073 \AA)$. Both crystal structures were solved by Patterson Methods using the program DIRDIF99 (Smits et al., 1994; Beurskens et al., 1999).

Data collection for both double salts was performed at low temperature $(100 \mathrm{~K})$ on the Oxford Diffraction Gemini S single-crystal diffractometer.

In every case, anisotropic least-squares refinement was carried out using SHELXL97 (Sheldrick, 2008) and all non-H atoms were refined anisotropically. At room temperature, $\mathrm{H}$ atoms were placed in ideal geometry, allowing them to ride on the $\mathrm{O}$ atom; the distance from every $\mathrm{H}$ atom to the central atom $(\mathrm{N})$ was fixed at $0.90 \pm 0.05 \AA$ using a DFIX geometrical restraint. Likewise, the non-bonded $\mathrm{H} \cdots \mathrm{H}$ distances in the ammonium ions were fixed at $1.47 \pm 0.05 \AA$. A common displacement coefficient was refined for all the $\mathrm{H}$ atoms. At $100 \mathrm{~K}$, the $\mathrm{H}$ atoms were located in the last stages of the refinement by a difference-Fourier and also isotropically refined by means of a common displacement coefficient.

A summary of the conditions for the data collection and the structure refinement parameters is given in Table $1 .^{\mathbf{1}}$ The crystallographic plots were obtained using ORTEP3 (Farrugia, 1997) and Mercury (Macrae et al., 2006).

For samples S1 and S2, experimental XRPD patterns were acquired in transmission mode on an Oxford Diffraction Xcalibur NOVA diffractometer, using $\mathrm{Cu} K \alpha$ radiation $(\lambda=$ $1.5418 \AA$ ), with an Onyx CCD area detector $(165 \mathrm{~mm})$. The powder patterns were collected using three $2 \theta$ detector positions $-82,0$ and 82 . For each detector position the sample was rotated $300^{\circ}$ on $\varphi$, with $300 \mathrm{~s}$ for each rotation, and finally the integrated data was averaged on the $2 \theta$ range $0-60^{\circ}$. Peak intensities were integrated over the entire ring in step-scan mode, using a step size of $0.02^{\circ}$.

Experimental XRPD patterns were acquired in transmission mode on an Oxford Diffraction Xcalibur diffractometer, NOVA, for samples S1 and S2, and Gemini S, for sample S3, using $\mathrm{Cu} K \alpha$ radiation $(\lambda=1.5418 \AA$ ), with an Onyx CCD area detector $(165 \mathrm{~mm})$ and a Ruby CCD area detector $(135 \mathrm{~mm})$, respectively. The powder patterns were collected using three $2 \theta$ detector positions $-82,0$ and 82 . For each detector position the sample was rotated $300^{\circ}$ on $\varphi$, with $300 \mathrm{~s}$ for each rotation, and finally the integrated data was averaged on the $2 \theta$ range 0 $60^{\circ}$ for samples S1 and S2, and $3-55^{\circ}$ for sample S3. Peak intensities were integrated over the entire ring in step-scan mode, using a step size of $0.02^{\circ}$ or $0.03^{\circ}$ for samples S1 and S2 or sample S3, respectively.

\footnotetext{
${ }^{1}$ Supplementary data for this paper are available from the IUCr electronic archives (Reference: KD5044). Services for accessing these data are described at the back of the journal.
}

Rietveld refinements were carried out via the FULLPROF program package (Rodriguez-Carvajal, 1990) using a pseudoVoigt peak-shape function for samples S1 and S2, and a Pearson VII function for sample S3. In least-squares cycles, the refined parameters were: zero-shift error, background coefficients (six-coefficients polynomial function), unit-cell parameters, peak-shape parameters ( $\eta$ for pseudo-Voigt and $m$ for Pearson VII), phase linewidths (from the Caglioti formula: $\mathrm{U}, \mathrm{V}$ and $\mathrm{W}$ for $\mathrm{S} 1, \mathrm{~V}$ and $\mathrm{W}$ for S2 and $\mathrm{W}$ for S3), an asymmetry parameter, and scale factor. Atoms were modelled as anisotropic, and for N3 nitrate (in the 3.1 salt) both orientations were included. Profile plots were obtained using WinPLOTR (Roisnel \& Rodriguez-Carvajal, 2000).

DSC analysis for sample S1 was carried out on a Metter Toledo DCS $822 \mathrm{e}$ calorimeter at $5 \mathrm{~K} \mathrm{~min}^{-1}$ in an $\mathrm{N}_{2}$ atmosphere.

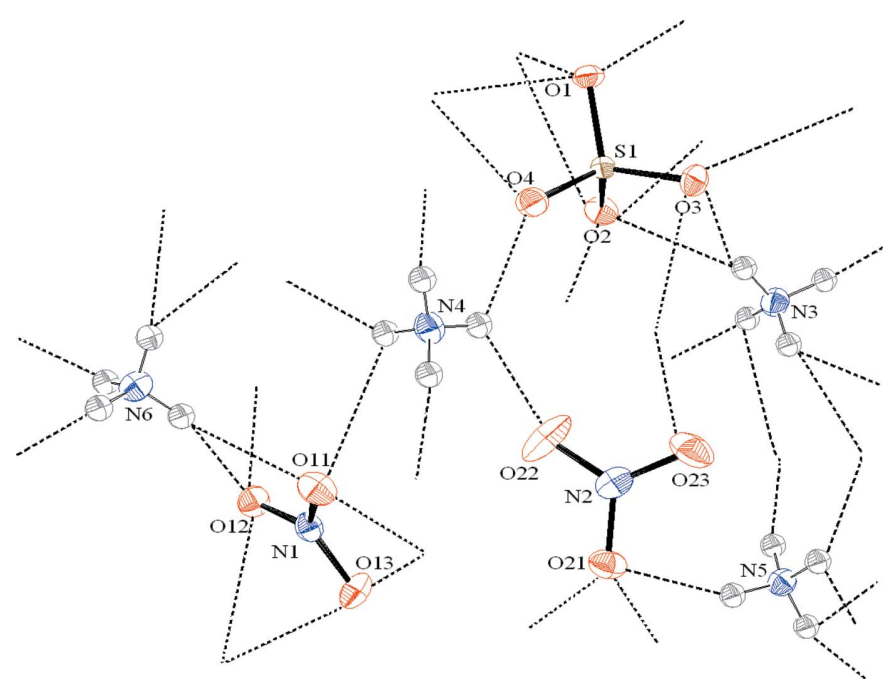

Figure 1

Asymmetric unit of the $2 \cdot 1$ salt at $100 \mathrm{~K}$ (ellipsoids $50 \%$ ). Dashed lines indicate hydrogen bonds.

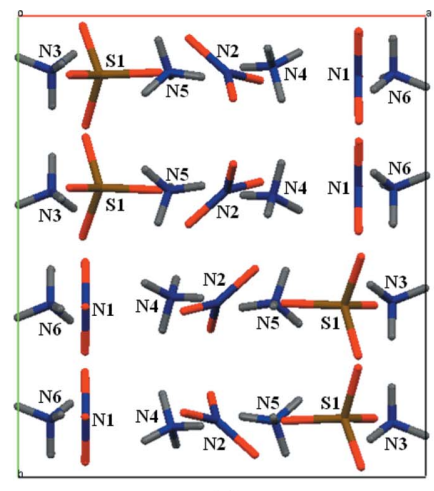

(a)

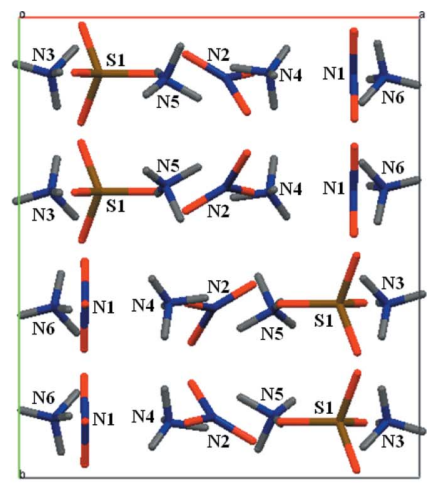

(b)
Figure 2

Perpendicular view to the $a b$ face in the 2.1 salt at $(a) 100 \mathrm{~K}$ and $(b)$ $293 \mathrm{~K}$. 
Table 2

Bond distances $(\AA)$ for the salt at the two temperatures.

Only distances for the major orientations are included.

\begin{tabular}{|c|c|c|c|c|}
\hline & \multicolumn{2}{|c|}{ 2AN.AS salt } & \multicolumn{2}{|c|}{ 3AN.AS salt } \\
\hline & $100 \mathrm{~K}$ & $293 \mathrm{~K}$ & $100 \mathrm{~K}$ & $293 \mathrm{~K}$ \\
\hline $\mathrm{S} 1-\mathrm{O} 1$ & $1.4776(9)$ & $1.471(2)$ & $1.4769(7)$ & $1.458(2)$ \\
\hline $\mathrm{S} 1-\mathrm{O} 2$ & $1.4793(9)$ & $1.471(2)$ & $1.4883(6)$ & $1.464(2)$ \\
\hline $\mathrm{S} 1-\mathrm{O} 3$ & $1.4874(9)$ & $1.472(2)$ & $1.4738(6)$ & $1.463(2)$ \\
\hline $\mathrm{S} 1-\mathrm{O} 4$ & $1.4654(9)$ & $1.456(2)$ & $1.4781(6)$ & $1.452(2)$ \\
\hline$\langle\mathrm{S}---\mathrm{O}\rangle$ & 1.4774 (9) & $1.468(2)$ & $1.4792(7)$ & $1.460(2)$ \\
\hline $\mathrm{N} 1-\mathrm{O} 11$ & $1.258(1)$ & $1.250(2)$ & $1.2580(9)$ & $1.255(4)$ \\
\hline $\mathrm{N} 1-\mathrm{O} 12$ & 1.255 (1) & $1.245(2)$ & 1.257 (1) & $1.218(3)$ \\
\hline $\mathrm{N} 1-\mathrm{O} 13$ & $1.248(1)$ & $1.250(3)$ & $1.246(1)$ & $1.232(4)$ \\
\hline $\mathrm{N} 2-\mathrm{O} 21$ & 1.269 (1) & $1.253(3)$ & $1.251(1)$ & $1.243(3)$ \\
\hline $\mathrm{N} 2-\mathrm{O} 22$ & 1.231 (1) & $1.252(3)$ & $1.252(1)$ & $1.254(3)$ \\
\hline $\mathrm{N} 2-\mathrm{O} 23$ & $1.251(1)$ & $1.187(8)$ & $1.2624(8)$ & $1.246(2)$ \\
\hline $\mathrm{N} 3-\mathrm{O} 31$ & & & $1.257(1)$ & $1.277(4)$ \\
\hline $\mathrm{N} 3-\mathrm{O} 32$ & & & 1.209 (1) & 1.169 (4) \\
\hline $\mathrm{N} 3-\mathrm{O} 33$ & & & $1.276(1)$ & $1.233(6)$ \\
\hline$\langle\mathrm{N}---\mathrm{O}\rangle$ & $1.252(1)$ & $1.239(8)$ & $1.252(1)$ & $1.236(6)$ \\
\hline
\end{tabular}

\section{Results and discussion}

\subsection{Double-salt structures}

The structure of both double salts is determined by the hydrogen-bonding network, with the $\mathrm{O}$ atoms as the acceptors.

The asymmetric unit of the $2 \cdot 1$ salt (at $100 \mathrm{~K}$ ) is shown in Fig. 1. The crystal presents an alternating layer structure of cations and anions, recognizable through the three faces of the cell. Fig. 2( $a$ ) shows the unit cell through the $a b$ face, with the ions situated in three different parallel layers.

At room temperature (see Fig. 2b) ammonium ions containing N4 and N5 modify their orientation appreciably,

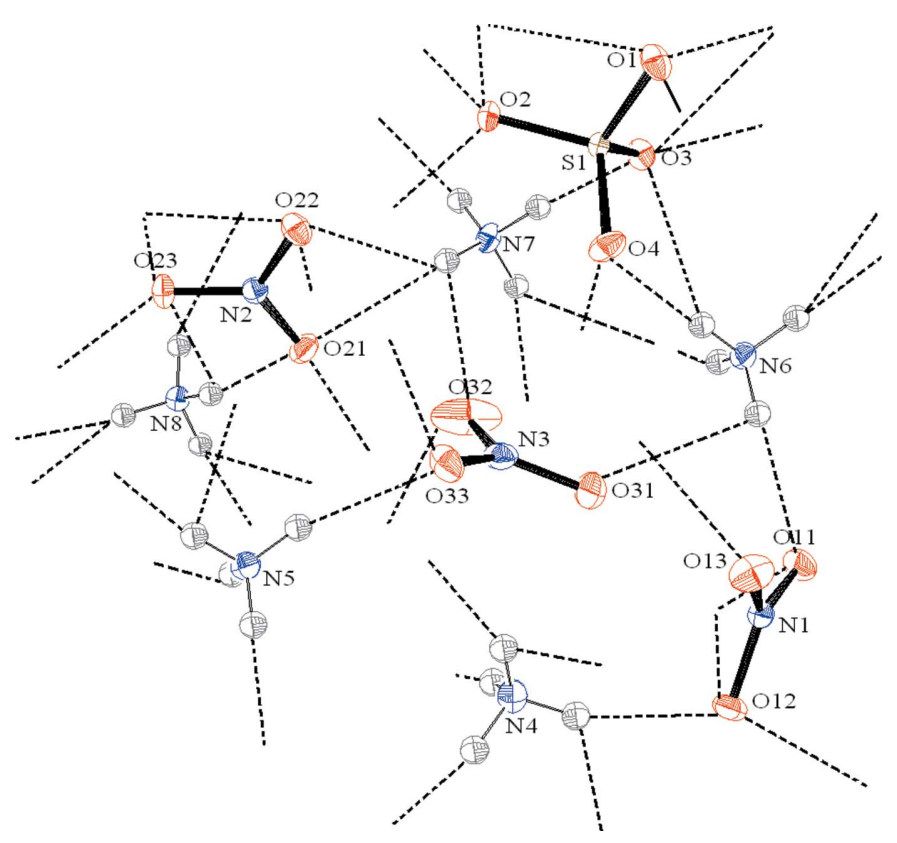

Figure 3

Asymmetric unit of the 3.1 salt at $100 \mathrm{~K}$ (ellipsoids 50\%). Dashed lines indicate hydrogen bonds. while nitrate $\mathrm{N} 2$ suffers a modification in the position of the oxygen groups, resulting in alterations of the distances in neighbouring atoms of up to 0.1 to $0.3 \AA$. The $\mathrm{O} 23$ atom was split into two positions (41:59, not shown here) to better model an apparent highly anisotropic displacement ellipsoid. Furthermore, the position of the $\mathrm{N}$ atom is also modified, resulting in a larger separation between neighbouring ions of around $0.35 \AA(5.193 \rightarrow 5.549 \AA)$.

The asymmetric unit of the 3.1 salt (at $100 \mathrm{~K}$ ) is shown in Fig. 3. The nitrate N3 shows a rotational disordered structure (not shown here) between two main positions. Unlike the $2 \cdot 1$ salt, this crystal presents an alternating layer structure of anions and cations visible only through two of the faces of the cell. This alternation may be seen in Fig. 4, representing the unit cell through the $b c$ face at both temperatures. Ammonium ions lie in three different parallel layers and anions in two other parallel layers (nitrates N1 and N3, and nitrate N2 and sulfate, respectively).

At $100 \mathrm{~K}$, a ratio of $82.5: 17.5$ is found for the two orientations of nitrate $\mathrm{N} 3$. The rotation angle between them is $37^{\circ}$ and they form planes with a dihedral angle of $9.8^{\circ}$. At room temperature, the population of the minor orientation is doubled (67.8:32.2), whereas the group angle and dihedral angle remain constant (39 and $10.7^{\circ}$, respectively).

The increase in temperature from 100 to $293 \mathrm{~K}$ implies the splitting into two positions (73:28, not shown here) of the oxygen $\mathrm{O} 11$ of the nitrate $\mathrm{N} 1$, and also induces a shortening in the $b$ axis (see Table 1). This result can be explained taking into account the different orientation of sulfate and nitrate anions in the crystal at the two temperatures (see Fig. 4). The sulfate anion is reoriented almost parallel to the ac face (the angle between the $\mathrm{O} 2-\mathrm{S} 1-\mathrm{O} 4$ atoms and the $a c$ face changes from $18.0^{\circ}$ at $100 \mathrm{~K}$ to $8.9^{\circ}$ at $293 \mathrm{~K}$, and the angle between $\mathrm{O} 2-\mathrm{S} 1-\mathrm{O} 4$ and $\mathrm{O} 2^{\prime}-\mathrm{S}^{\prime}{ }^{\prime}-\mathrm{O} 4^{\prime}$ changes from 32.4 to $16.7^{\circ}$ ). This reorientation decreases the $\mathrm{O} 1 \cdots \mathrm{O} 3$ interatomic distance from 3.688 to $3.570 \AA$.

The nitrate anion $\mathrm{N} 1$ is also reoriented and the angle between the $\mathrm{N} 1-\mathrm{O} 11$ bond and the $a c$ face changes from 24.6
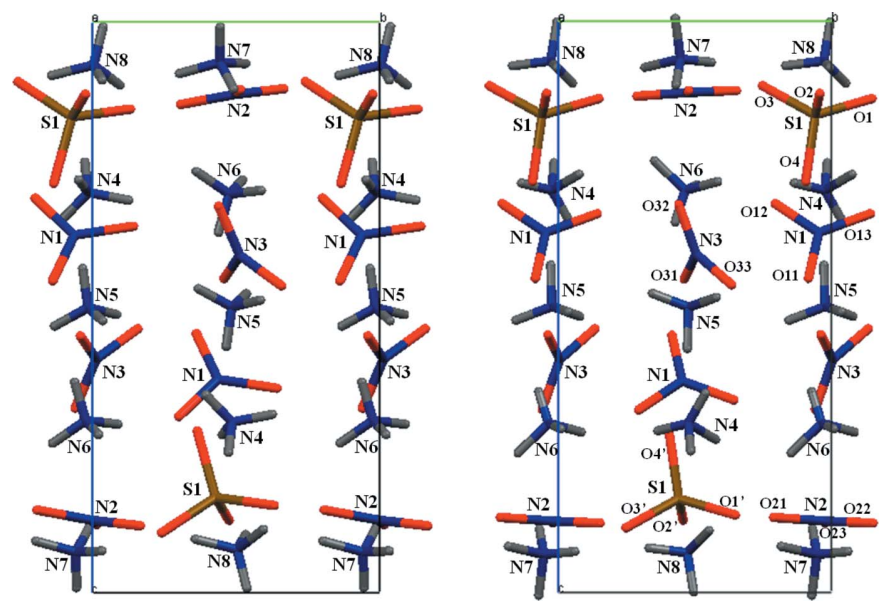

Figure 4

Perpendicular view to the $b c$ face in the 3.1 salt at $(a) 100 \mathrm{~K}$ and $(b)$ $293 \mathrm{~K}$. 
Table 3

Hydrogen-bond parameters $\left(\AA,^{\circ}\right)$ for the $2 \cdot 1$ and $3 \cdot 1$ salts at $100 \mathrm{~K}$ and at $293 \mathrm{~K}$ (italics).

\begin{tabular}{|c|c|c|c|}
\hline Hydrogen bond & $D \cdots A(\AA)$ & $\mathrm{H} \cdots A(\AA)$ & $D-\mathrm{H} \cdots A\left(^{\circ}\right)$ \\
\hline \multicolumn{4}{|l|}{$2 \cdot 1$ salt } \\
\hline \multirow[t]{2}{*}{$\mathrm{N} 3-\mathrm{H} 3 C \cdots \mathrm{O} 3$} & $2.918(2)$ & $2.09(2)$ & $165(2)$ \\
\hline & $3.026(3)$ & $2.24(5)$ & $149(4)$ \\
\hline \multirow{2}{*}{$\mathrm{N} 3-\mathrm{H} 3 A \cdots \mathrm{O} 3^{\mathrm{i}}$} & $2.916(2)$ & $2.05(2)$ & $163(2)$ \\
\hline & $2.939(3)$ & $2.11(4)$ & $150(4)$ \\
\hline \multirow[t]{2}{*}{$\mathrm{N} 3-\mathrm{H} 3 D \cdots \mathrm{O} 1^{\mathrm{ii}}$} & 2.909 (1) & $2.04(1)$ & $168(2)$ \\
\hline & $3.011(3)$ & $2.18(3)$ & $155(3)$ \\
\hline \multirow{2}{*}{$\mathrm{N} 5-\mathrm{H} 5 A \cdots \mathrm{O} 2^{\mathrm{ii}}$} & $2.815(1)$ & $1.95(1)$ & $175(1)$ \\
\hline & $2.853(3)$ & $2.10(4)$ & $155(4)$ \\
\hline \multirow{2}{*}{$\mathrm{N} 4-\mathrm{H} 4 C \cdots \mathrm{O} 3^{\mathrm{iii}}$} & 2.819 (1) & $1.96(2)$ & $162(2)$ \\
\hline & $2.860(3)$ & $2.07(4)$ & $155(4)$ \\
\hline \multirow{2}{*}{$\mathrm{N} 5-\mathrm{H} 5 D \cdots \mathrm{O} 4^{\mathrm{iv}}$} & $2.941(2)$ & $2.09(2)$ & $167(2)$ \\
\hline & 3.132 (4) & $2.33(4)$ & $160(4)$ \\
\hline \multirow[t]{2}{*}{$\mathrm{N} 6-\mathrm{H} 6 C \cdots \mathrm{O} 1^{\mathrm{v}}$} & $2.919(2)$ & $2.04(2)$ & $166(2)$ \\
\hline & $2.928(3)$ & $2.04(3)$ & $169(3)$ \\
\hline \multirow[t]{2}{*}{$\mathrm{N} 6-\mathrm{H} 6 D \cdots \mathrm{O} 2^{\mathrm{vi}}$} & $2.962(2)$ & $2.13(2)$ & $162(2)$ \\
\hline & $3.032(3)$ & $2.28(4)$ & $146(3)$ \\
\hline \multicolumn{4}{|l|}{$3 \cdot 1$ salt } \\
\hline \multirow[t]{2}{*}{$\mathrm{N} 6-\mathrm{H} 6 D \cdots \mathrm{O} 4$} & $2.865(1)$ & $2.02(2)$ & $176(2)$ \\
\hline & 3.048 (4) & $2.19(3)$ & $172(3)$ \\
\hline \multirow[t]{2}{*}{$\mathrm{N} 7-\mathrm{H} 7 C \cdot \cdots \mathrm{O} 3$} & $2.850(1)$ & $1.95(1)$ & $169(1)$ \\
\hline & $2.958(3)$ & $2.25(3)$ & $141(3)$ \\
\hline \multirow[t]{2}{*}{$\mathrm{N} 8-\mathrm{H} 8 C \cdots \mathrm{O} 21$} & 2.889 (1) & $2.02(2)$ & $163(1)$ \\
\hline & 3.004 (3) & $2.32(3)$ & $140(3)$ \\
\hline \multirow[t]{2}{*}{$\mathrm{N} 4-\mathrm{H} 4 D \cdots \mathrm{O} 2^{\mathrm{vii}}$} & $2.823(1)$ & $1.97(1)$ & $174(1)$ \\
\hline & $2.847(2)$ & $1.94(2)$ & $170(2)$ \\
\hline \multirow{2}{*}{$\mathrm{N} 5-\mathrm{H} 5 D \cdots \mathrm{O} 4^{\mathrm{vii}}$} & $2.766(1)$ & $1.92(1)$ & $169(1)$ \\
\hline & $2.754(2)$ & $1.87(2)$ & $165(2)$ \\
\hline \multirow[t]{2}{*}{$\mathrm{N} 5-\mathrm{H} 5 B \cdots \mathrm{O} 13^{\mathrm{vii}}$} & $2.910(1)$ & $2.08(2)$ & $165(2)$ \\
\hline & $2.970(3)$ & 2.25 (3) & $143(3)$ \\
\hline \multirow[t]{2}{*}{$\mathrm{N} 4-\mathrm{H} 4 C \cdots \mathrm{O} 33^{\mathrm{vii}}$} & $2.908(2)$ & $2.07(2)$ & $178(2)$ \\
\hline & $2.999(7)$ & $2.23(2)$ & $162(3)$ \\
\hline \multirow[t]{2}{*}{$\mathrm{N} 8-\mathrm{H} 8 A \cdots \mathrm{O} 23^{\mathrm{viii}}$} & $2.981(1)$ & $2.08(2)$ & $170(2)$ \\
\hline & 3.037 (3) & $2.20(3)$ & $149(3)$ \\
\hline \multirow[t]{2}{*}{$\mathrm{N} 7-\mathrm{H} 7 B \cdots \mathrm{O} 2^{\text {viii }}$} & $2.877(1)$ & $2.00(2)$ & $159(1)$ \\
\hline & 3.009 (4) & $2.37(3)$ & $125(3)$ \\
\hline \multirow[t]{2}{*}{$\mathrm{N} 6-\mathrm{H} 6 C \cdots \mathrm{O} 1^{\mathrm{viii}}$} & $2.853(1)$ & $1.97(2)$ & $170(2)$ \\
\hline & $2.853(3)$ & 1.89 (3) & $172(3)$ \\
\hline \multirow[t]{2}{*}{$\mathrm{N} 7-\mathrm{H} 7 A \cdots \mathrm{O} 2^{\mathrm{ix}}$} & $2.920(1)$ & $2.10(1)$ & $167(1)$ \\
\hline & 2.969 (2) & $2.10(2)$ & $153(2)$ \\
\hline \multirow[t]{2}{*}{$\mathrm{N} 8-\mathrm{H} 8 B \cdots \mathrm{O} 1^{\mathrm{x}}$} & $2.848(1)$ & $1.99(1)$ & $174(1)$ \\
\hline & $2.998(3)$ & $2.27(3)$ & $145(2)$ \\
\hline
\end{tabular}

Symmetry codes: (i) $-x,-y,-z+1$; (ii) $x,-y+\frac{1}{2}, z+\frac{1}{2}$; (iii) $-x+1,-y,-z+1$; (iv) $x, y, z+1$; (v) $-x+1, y+\frac{1}{2},-z+\frac{1}{2}$; (vi) $x+1, y, z$; (vii) $-x+2, y-\frac{1}{2},-z+1$; (viii) $x, y-1, z$; (ix) $-x+2, y-\frac{1}{2},-z+2$; (x) $x+1, y-1, z$.

to $12.6^{\circ}$. Consequently, the $\mathrm{O} 12 \cdots \mathrm{O} 13$ distance between neighbouring ions shortens from 8.034 to $8.001 \AA$ (0.03 $\AA$ ).

The nitrate $\mathrm{N} 2$ remains almost perpendicular to the $a c$ face (from $80.7^{\circ}$ at $100 \mathrm{~K}$ to $86.7^{\circ}$ at $293 \mathrm{~K}$ ), thus moving the $\mathrm{N} 2-$ $\mathrm{O} 23$ bond to a parallel position to the face (from $5.1^{\circ}$ at $100 \mathrm{~K}$ to $1.7^{\circ}$ at $\left.293 \mathrm{~K}\right)$. Consequently, the O21..O22 distance between neighbouring ions scarcely varies (it shortens from 8.109 to $8.094 \AA$ ).

The angle between the nitrate $\mathrm{N} 3$ and the $a c$ face changes from $41.97^{\circ}$ at $100 \mathrm{~K}$ to $36.7^{\circ}$ at $293 \mathrm{~K}$, and the distance $\mathrm{O} 31 \cdots \mathrm{O} 33$ between neighbouring ions shortens from 7.374 to $7.194 \AA$ A.

Finally, both double salts show an apparent shortening of the $\mathrm{S}-\mathrm{O}$ and $\mathrm{N}-\mathrm{O}$ distances with increasing temperature (Table 2 ), but these results are a consequence of the increased librational motion of the $\mathrm{O}$ atoms around the $\mathrm{N}$ and $\mathrm{S}$ central atoms, leading to an underestimation of the $\mathrm{S}-\mathrm{O}$ and $\mathrm{N}-\mathrm{O}$ distances (the largest apparent shortenings are for the $\mathrm{O}$ atom with the largest anisotropy factors, $\mathrm{O} 23$ in salt $2 \cdot 1$, and $\mathrm{O} 11$ and $\mathrm{O} 32$ in salt $3 \cdot 1$ ). Prior experimental evidence of this phenomenon has been reported for the sulfate anion (Jacobsen et al., 2003), and nitrate anion (Jaskólski \& Olovsson, 1989; Nemec et al., 2001), with similar distances for these bonds to those shown in this article.

Nevertheless, the real $\mathrm{S}-\mathrm{O}$ distance at room temperature for the $\mathrm{SO}_{4}^{2-}$ groups considering a TLS analysis (translation, libration and screw motion) is 1.484 (2) $\AA$ (Jacobsen et al., 1998). On the other hand, a riding motion effect study (Jaskólski \& Olovsson, 1989) indicates a mean value of 1.262 (3) $\AA$ for the $\mathrm{NO}_{3}^{-}$anion. Both values are greater than our data at $100 \mathrm{~K}$.

\subsection{Hydrogen-bond network}

The hydrogen-bonding networks were located using PARST95 (Nardelli, 1995) and PLATON (Spek, 2002) under the conditions: $d(D \cdots A)<3.20 \AA, d(\mathrm{H} \cdots A)<R(\mathrm{H})+R(A)$, $\alpha(D-\mathrm{H} \cdots A)>100^{\circ}$, where $R$ represents the van der Waals radii (1.20 $\AA$ for $\mathrm{H}$ and $1.40 \AA$ for O; Dean, 1985; Lide, 1999).

A total of 25 hydrogen bonds were found for the 2.1 salt. Selected strong bonds are shown in Table 3 (a complete list is given in the supplementary material). All the $\mathrm{H}$ atoms are involved in hydrogen bonds at both temperatures. Increasing the temperature produces modifications shorter than $0.4 \AA$. At $100 \mathrm{~K}$, the four $\mathrm{O}$ atoms in the sulfate anion participate in 12 hydrogen bonds. Eight of them have distances shorter than $2.15 \AA$ and angles greater than $160^{\circ}$. At room temperature, the sulfate maintains six hydrogen bonds shorter than $2.18 \AA$ with an angle greater than $150^{\circ}$.

Nitrates participate in the hydrogen network through the $\mathrm{O}$ atoms. Nitrate N1 participates in eight hydrogen bonds. On increasing the temperature, all of them become shorter except for one. Nitrate N2 participates in five hydrogen bonds. On increasing the temperature, all bonds enlarge except for one.

A total of 37 hydrogen bonds were found for the 3.1 salt. Selected strong bonds are shown in Table 3 (a complete list is given in the supplementary material). As in the previous case, every $H$ atom participates in hydrogen bonds at both temperatures and an increase in the temperature leads, in the majority of cases, to alterations in distances of less than $0.4 \AA$.

The sulfate anion in salt $3 \cdot 1$ behaves very similarly at $100 \mathrm{~K}$ to that of salt $2 \cdot 1$. The four $\mathrm{O}$ atoms participate in 12 hydrogen bonds, eight of which are shorter than $2.15 \AA$ and present an angle greater than $155^{\circ}$. At room temperature, the sulfate maintains six hydrogen bonds shorter than $2.20 \AA$ with an angle greater than $150^{\circ}$.

Nitrates participate in the hydrogen network through the $\mathrm{O}$ atoms. Nitrate N1 participates in six hydrogen bonds, nitrate N2 participates in nine hydrogen bonds, and nitrate N3 participates in ten hydrogen bonds (five with each orientation). Increasing the temperature every hydrogen bond but two in nitrate N3 becomes weaker (longer), causing the 
populations of both orientations to move closer and increasing significantly the disorder of the anion.

\subsection{Sample quantification}

Some advances in the semiquantitative analysis of (phosphonate) fertilizers using a calibration curve with an internal standard have been published previously, obtaining standard deviations in the $10-15 \%$ range for the major components (Ando \& Akiyama, 1964; Ando et al., 1965; Cekinski, 1987). Recently, Highsmith et al. (2002) proposed the quantification

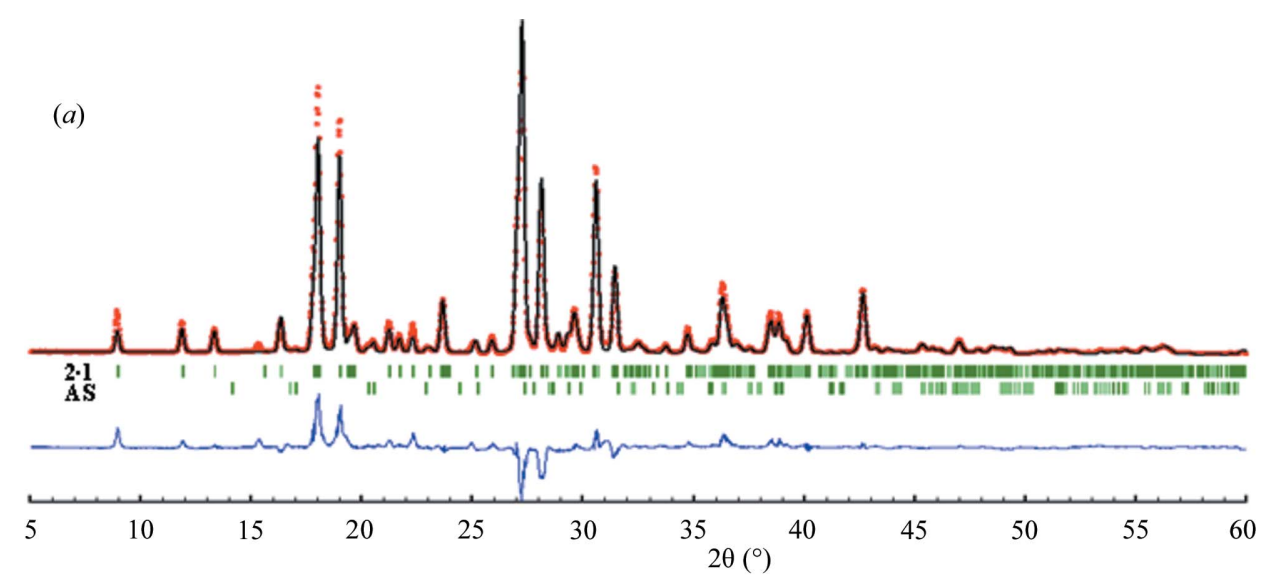

(b)

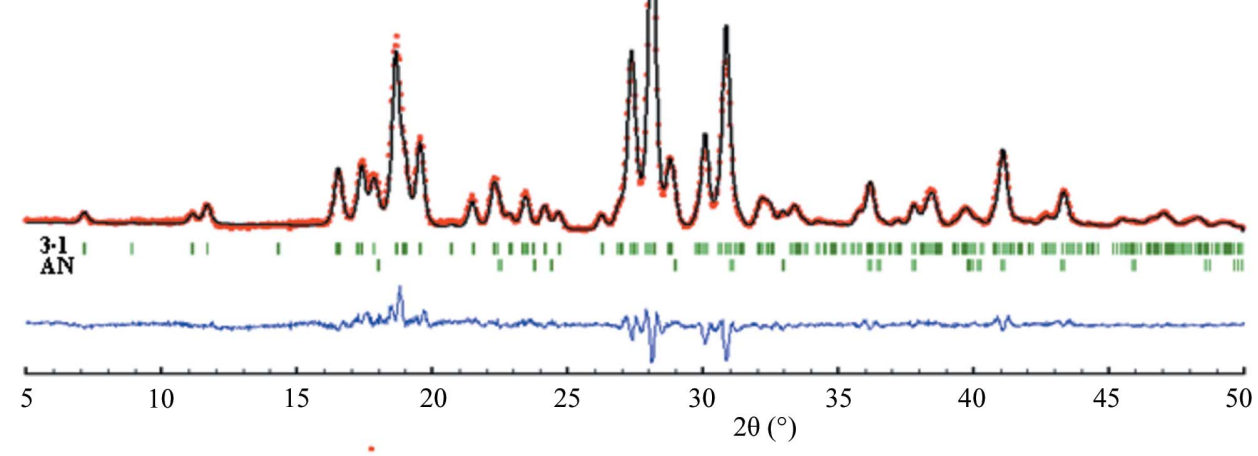

(c)

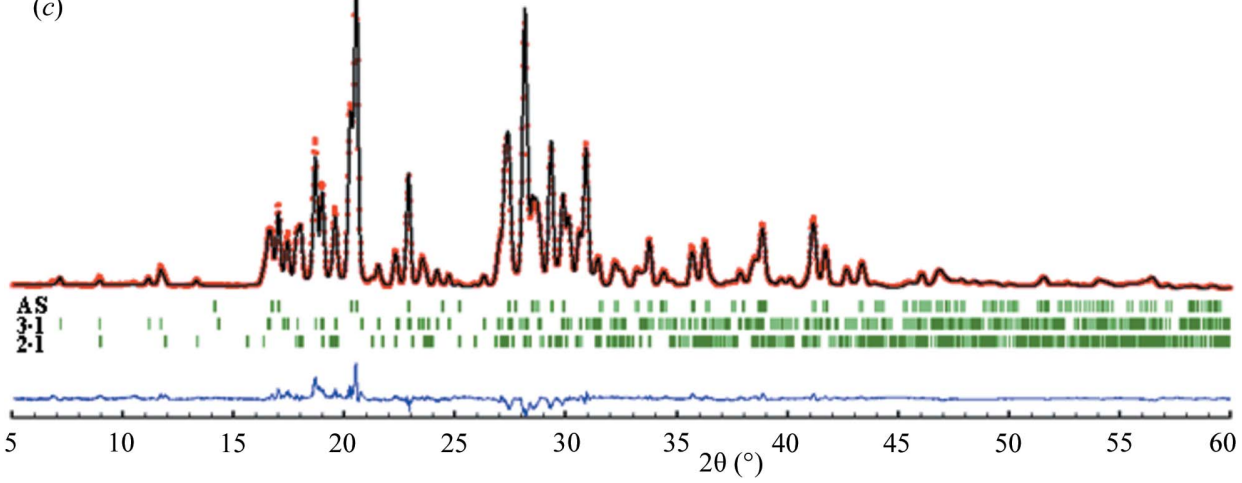

Figure 5

Rietveld refinement for samples S2 [double salt $2 \cdot 1$ and AS] (a), S3 [double salt 3.1 and AN] (b) and S1 [AS and double salts $3 \cdot 1$ and 2.1] (c). of ASN fertilizers using the Matrix Flushing [Normalized RIR] method (Snyder, 1992), but with errors of around 5\% and a reproducibility of $\pm 2 \%$.

Now, the knowledge of the crystal structures of the double salts $2 \mathrm{AN}$.AS and 3AN.AS allows the use of the Rietveld method for quantifying phases in NSA fertilizers. Validation of this method is shown for several samples used in this study.

3.3.1. Analysis of sample S2 (salt 2.1). From the experimental profile (Fig. $5 a$ ) we can conclude that this sample is not the 2.1 pure phase. Several peaks from free AS and a peak from an unknown phase $\left(2 \theta \simeq 15.2^{\circ}\right)$ are observed (preliminary unpublished results in 2009 seem to indicate a monohydrate double salt of AS and AN). Rietveld refinement shows 1.4 (1)\% of free AS with fitting values of $R_{\mathrm{B}}=0.147$ and $R_{\mathrm{F}}=0.080$ for the $2 \cdot 1$ salt and $R_{\mathrm{B}}=0.179$ and $R_{\mathrm{F}}=0.098$ for the ammonium sulfate. The high values of these parameters result from the presence of the unidentified phase and mainly from an overestimation of the experimental intensity in the peaks at low angles (related to the diffractometer used).

3.3.2. Analysis of sample S3 (salt 3.1). The experimental profile shows that the solid contains a low percentage of AN (IV) in addition to the $3 \cdot 1$ salt. Three different aliquots of the sample were analysed by means of the Rietveld method (Fig. $5 b$ shows one of them), obtaining a mean composition of 95.1 (9)\% of the double salt and $4.9(2) \%$ of $\mathrm{AN}$. $R_{\mathrm{B}}=0.070$ and $R_{\mathrm{F}}=0.034$ for the 3.1 salt and $R_{\mathrm{B}}=0.049$ and $R_{\mathrm{F}}=0.029$ for the ammonium nitrate. Additional studies were performed using DSC (supplementary material). The presence of the phase-change endotherm II-I at $398 \mathrm{~K}$ (Ingman et al., 1982) and the much weaker peak from the phase-change endotherm IV-II ( $\sim 325 \mathrm{~K}$ ) confirm the existence of $\mathrm{AN}$ in the sample. Change between IV and III depends on impurities, water content and/ or the thermal history of the solid, lying usually between 305 and $328 \mathrm{~K}$. Under some 
experimental conditions, however, phase II and IV are both metastable with respect to phase III. For more details see Choi et al. (1972), Ingman et al. (1982), Kim (1997) and Simoes et al. (1998).

3.3.3. Analysis of sample $\mathbf{S 1}$ (fertilizer). Elemental analysis of the sample shows $98.5 \%$ of AN and AS; the other $1.5 \%$ are minor phases (iron aluminium sulfates, anti-caking stabilizers ...). . From the Rietveld refinement shown in Fig. 5(c), a phase composition of 32.4 (2)\% free AS, 17.5 (3)\% salt 2.1 and $48.6(4) \%$ salt 3.1 can be obtained (percentages normalized to $98.5 \%$ ). The quality of the fit is very high, both graphically and numerically, with $R_{\mathrm{B}}$ and $R_{\mathrm{F}}$ values of 0.050 , 0.029 (free SA), 0.054, 0.038 (salt 2.1) and 0.054, 0.030 (salt $3 \cdot 1)$.

\section{Conclusions}

The structures of the double salts $2 \mathrm{AN} \cdot \mathrm{AS}$ and $3 \mathrm{AN} \cdot \mathrm{AS}$, the main constituents of NSA fertilizers and of aerosol particles, have been solved at room temperature and at $100 \mathrm{~K}$. Both structures are controlled by a dense hydrogen-bonding network with $\mathrm{O}$ atoms acting as the acceptors. Both salts present a distribution of alternating layers of anions and cations. In the 3.1 salt, one of the nitrates is disordered in two major orientations.

Increasing the temperature results in a shortening of the $b$ axis in the 3.1 salt as a consequence of the displacement of sulfate and nitrate ions. Increasing the temperature likewise causes equalization of both orientations for the disordered nitrate. Industrial samples of fertilizers may be easily quantified using a Rietveld refinement with the reported crystal structures, obtaining excellent results.

The authors gratefully acknowledge Fertiberia S.A. for supplying samples S1 and S2, FEDER funding, Projects MEC06-MAT-2006-01997, MEC-06-CTQ2006-14644-C02-01 and Factoría Española de Cristalización - CSD2006-00015 for financial support. Our thanks also to the X-ray Single Crystal Diffraction and Thermocalorimetric and Elemental Analysis Units belonging to the University of Oviedo Scientific Technical Services for the measurements carried out at their facilities. The authors also want to acknowledge the co-editor and two anonymous referees for their corrections and suggestions.

\section{References}

AAPFCO (2009). Association of American Plant Food Control Officials, Missouri, USA, http://www.aapfco.org/.

Amundson, N. R., Caboussat, A., He, J. W., Martynenko, A. V., Savarin, V. B., Seinfeld, J. H. \& Yoo, K. Y. (2006). Atmos. Chem. Phys. 6, 975-992.

Ando, J. \& Akiyama, T. (1964). Bunseki Kagaku, 13, 717-725.

Ando, J., Smith, J. P., Siegel, M. R. \& Jordan, J. E. (1965). J. Agric. Food Chem. 13, 186-195.

Beurskens, P. T., Beurskens, G., De Gelder, R., Garcia-Granda, S., Israel, R., Gould, R. O. \& Smits, J. M. M. (1999). DIRDIF-99. Crystallography Laboratory, University of Nijmegen, The Netherlands.
Blessing, R. H. (1995). Acta Cryst. A51, 33-38.

Blessing, R. H. (1997). J. Appl. Cryst. 30, 421-426.

Bokii, G. B. \& Burovaya, E. E. (1937). Mem. Soc. Russ. Mineral. 66, 45-46.

Bothe, J. R. \& Beyer, K. D. (2007). J. Phys. Chem. A, 111, 1210612117.

Burla, M. C., Caliandro, R., Camilli, M., Carrozzini, B., Cascararno, G. L., De Caro, L., Giacovazzo, C., Polidori, G. \& Spagna, R. (2005). J. Appl. Cryst. 38, 381-388.

Cekinski, E. (1987). Fertilizantes, 9, 10-13.

Choi, C. S., Mapes, J. E. \& Prince, E. (1972). Acta Cryst. B28, 13571361.

Clegg, S. L., Brimblecombe, P. \& Wexler, A. S. (1998). J. Phys. Chem. A, 102, 2137-2154.

Coates, R. V. \& Woodard, G. D. (1963). J. Sci. Food Agric. 14, 398404.

Dean, J. A. (1985). Editor. Lange's Handbook of Chemistry, 13th ed. New York: McGraw-Hill Book Company.

Farrugia, L. J. (1997). J. Appl. Cryst. 30, 565.

Ghosh, S. K., Srinivasa, V. K. \& Banerjee, B. K. (1965). Indian J. Phys. 39, 143-144.

Harrison, R. M. \& Sturges, W. T. (1984). Atmos. Environ. 18, 1829 1833.

Highsmith, R. E., Kweeder, J. A. \& Correale, S. T. (2002). US Patent 0095966A1.

Ingman, J. S., Kearley, G. J. \& Kettle, S. F. A. (1982). J. Chem. Soc. Faraday Trans. 1, 78, 1817-1826.

Jacobsen, S. D., Smyth, J. R. \& Swope, R. J. (1998). Can. Mineral. 36, 1053-1060.

Jacobsen, S. D., Smyth, J. R. \& Swope, R. J. (2003). Phys. Chem. Miner. 30, 321-329.

Jänecke, E., Eissner, W. \& Brill, R. (1927). Z. Anorg. Allg. Chem. 160, 171-184.

Jaskólski, M. \& Olovsson, I. (1989). Acta Cryst. B45, 78-85.

Jassal, H. S. \& Kumar, R. (2004). Fertilizer News, 49, 35-38.

Kim, J. H. (1997). J. Chem. Eng. Jpn, 30, 336-338.

Lehr, J. R., Brown, E. H., Frazier, A. W., Smith, J. P. \& Thrasher, R. D. (1967). Chem. Eng. Bull. 6, 166.

Lide, D. R. (1999). Editor. Handbook of Chemistry and Physics, 80th ed. Boca Raton: CRC Press.

Ling, T. Y. \& Chan, C. K. (2007). Environ. Sci. Technol. 41, 80778083.

Macrae, C. F., Edgington, P. R., McCabe, P., Pidcock, E., Shields, G. P., Taylor, R., Towler, M. \& van de Streek, J. (2006). J. Appl. Cryst. 39, 453-457.

Malquori, A. \& Cecconi, S. (1964). Chim. Ind. (Milan), 46, 637-647.

Martin, S. T., Hung, H. M., Park, R. J., Jacob, D. J., Spurr, R. J. D., Chance, K. V. \& Chin, M. (2004). Atmos. Chem. Phys. 4, 183214.

Martin, S. T., Schlenker, J. C., Malinowski, A., Hung, H. M. \& Rudich, Y. (2003). Geophys. Res. Lett. 30, ASC 6/1-6/4.

Meline, R. S., McCamy, I. W., Graham, J. L. \& Sloan, T. S. (1968). J. Agric. Food Chem. 16, 235-240.

Misovic, J. \& Ramasechan, R. (1963). Glasnik Hem. Drustva Beograd. 28, 115-122.

Nardelli, M. (1995). J. Appl. Cryst. 28, 659.

Nemec, I., Císarová, I. \& Micka, Z. (2001). J. Solid State Chem. 158, $1-13$.

Nonius BV (1997-2000). COLLECT. Nonius BV, Delft, The Netherlands.

Osaka, Y. \& Inouye, R. (1925). Jpn. J. Chem. 2, 87-98.

Otwinowski, Z. \& Minor, W. (1997). Methods in Enzymology, Part A, edited by C. W. Carter \& R. M. Sweet, Vol. 276, pp. 307-326. New York. Academic Press.

Oxford Diffraction (1995-2003). Xcalibur PX Software. Oxford Diffraction Ltd, Abingdon, Oxfordshire, England.

Oxford Diffraction (2006a). CrysAlisPro CCD. Oxford Diffraction Ltd, Abingdon, Oxfordshire, England. 
Oxford Diffraction (2006b). CrysAlisPro RED (including ABSPACK). Oxford Diffraction Ltd, Abingdon, Oxfordshire, England.

Rodriguez-Carvajal, J. (1990). FULLPROF. Abstracts of the Satellite Meeting on Powder Diffraction of the XV Congress of the IUCr, p. 127, Toulouse, France.

Roisnel, T. \& Rodriguez-Carvajal, J. (2000). Mater. Sci. Forum, 378381, 118-123.

Schlenker, J. C., Malinowski, A., Martin, S. T., Hung, H. M. \& Rudich, Y. (2004). J. Phys. Chem. A, 108, 9375-9383.

Schlenker, J. C. \& Martin, S. T. (2005). J. Phys. Chem. A, 109, 99809985.

Schreinemakers, F. A. H. \& Hoenen, P. H. J. (1909). Chem. Week, 6, $51-56$.
Sheldrick, G. M. (2008). Acta Cryst. A65, 112-122.

Simoes, P. N., Pedroso, L. M., Portugal, A. A. \& Campos, J. L. (1998). Thermochim. Acta, 319, 55-65.

Smith, J. P., Lehr, J. R. \& Frazier, A. W. (1962). J. Agric. Food Chem. 10, 77-78.

Smits, J. M. M., Smykalla, C., Buerskens, P. T., Bosman, W. P. \& García-Granda, S. (1994). J. Appl. Cryst. 27, 661-665.

Snyder, R. L. (1992). Powder Diffr. 7, 186-193.

Sokolov, V. A. (1938). Bull. Acad. Sci. USSR, 1, 123-135.

Spek, A. L. (2002). PLATON. Utrecht University, The Netherlands.

Srinivasa, V. K., Ghosh, S. K. \& Banerjee, B. K. (1964). Technology, 1, 3-7.

Wexler, A. S. \& Clegg, S. L. (2002). J. Geophys. Res. 107, 42074212. 